\title{
Unrecognized catatonia as a cause for delayed weaning in Intensive Care Unit
}

\author{
Rupesh Gupta, Saurabh Saigal ${ }^{1}$, Rajnish Joshi, Praveen Tagore, Nirendra Rai ${ }^{2}$ Krishna Prasad ${ }^{3}$
}

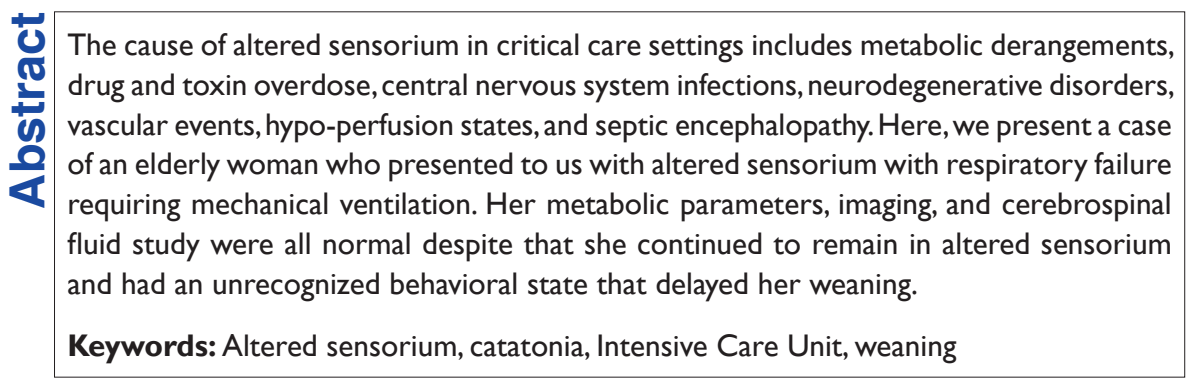

\section{Introduction}

Altered behavior is a common occurrence in critically ill patients, and has diverse etiologies. The situations are further complicated in elderly, those with underlying co-morbidities and in individuals on mechanical ventilation. We describe an elderly woman, who developed sepsis and respiratory failure, required mechanical ventilation, and had an unrecognized behavioral state that delayed her weaning.

\section{Case Report}

A 68-year-old woman with previous hypothyroidism and bipolar disorder was on multiple medications (sodium valproate, clozapine, risperidone, and trihexyphenidyl) for two decades. A day prior to admission, she became drowsy, without any limb weakness. She was hypothermic, had pulse of $50 / \mathrm{min}$, blood pressure of $90 / 60 \mathrm{mmHg}$, respiratory rates of $24 / \mathrm{min}$, and her bilateral plantars were mute. She had crepitations over right lower lung fields. On laboratory evaluation, she had pancytopenia and normal renal and liver function tests.

From:

Departments of Medicine, ${ }^{1}$ Trauma and Emergency Medicine, ${ }^{2}$ Neurology and ${ }^{3}$ Psychiatry, AlIMS, Bhopal, Madhya Pradesh, India

\section{Correspondence:}

Dr. Saurabh Saigal, Department of Trauma and Emergency Medicine, AlIMS Bhopal, Saket Nagar, Bhopal, Madhya Pradesh, India.

E-mail: saurabh.criticalcare @aiimsbhopal.edu.in

\begin{tabular}{|l|}
\hline Access this article online \\
\hline Website: www.ijccm.org \\
\hline DOI: 10.4103/0972-5229.169360 \\
\hline Quick Response Code: \\
\hline \\
\hline
\end{tabular}

Chest radiograph revealed right lower and middle lobe consolidation. She was started on crystalloids, antibiotics, and hydrocortisone for sepsis due to right lower zone pneumonia. Her previous drugs were withheld given the possibility of drug-induced pancytopenia due to either clozapine or valproate. Her thyroid functions were done, and her thyroid-stimulating hormone was $22.86 \mathrm{mIU} / \mathrm{L}$, with normal FT4 and FT3 levels. Her anti-thyroid peroxidase antibodies were negative. Her thyroxine dose was escalated to $100 \mathrm{mcg} /$ day. On $3^{\text {rd }}$ day, her respiratory distress worsened and became more drowsy. She was intubated and initiated on mechanical ventilation, and vasopressors were started. By day 7, sedatives were tapered, her infection was brought under control, and vasopressors were stopped. However, she remained lethargic, and had poor respiratory efforts, for which percutaneous tracheostomy was performed on D10. Magnetic resonance imaging brain, cerebrospinal

This is an open access article distributed under the terms of the Creative Commons Attribution-NonCommercial-ShareAlike 3.0 License, which allows others to remix, tweak, and build upon the work non-commercially, as long as the author is credited and the new creations are licensed under the identical terms.

For reprints contact: reprints@medknow.com

How to cite this article: Gupta R, Saigal S, Joshi R, Tagore P, Rai N, Prasad K. Unrecognized catatonia as a cause for delayed weaning in Intensive Care Unit. Indian J Crit Care Med 2015;19:693-4. 
fluid examination, total creatine kinase levels, and electroencephalography were normal. She persisted to be lethargic, with a fixed gaze, limited blinking, fixed flexor posturing, and muscle tone was increased in all limbs. A psychiatry opinion was taken, and provisional diagnosis of catatonia was made. Lorazepam test was performed, the rigidity of her limbs improved. She was initiated on intravenous (IV) lorazepam, i.e. $2 \mathrm{mg}$ IV q8h. Over next 5 days, she became fully conscious. By day 24, she could be weaned off ventilator. As her neuromuscular power improved, tracheostomy tube was removed and stoma was strapped. The patient was discharged after 35 days of hospital stay, and is doing well 6 months later.

\section{Discussion}

Catatonia is a neuropsychiatric syndrome of altered mental status and characteristic psychomotor findings. Clinically, catatonia is characterized by excited or withdrawn features, though patients manifest some of both types during the course of their illness. ${ }^{[1]}$ Its exact prevalence within the Intensive Care Unit (ICU) is unknown, with one report on a small number of patients suggesting it may affect up to $4 \%$ of critically ill patients. ${ }^{[2]}$

In our case, there were various risk factors for catatonia such as old age, affective disorder, withdrawal of antipsychotics, and chronic medical illness. Other likely differentials in this case with altered sensorium can be metabolic disorders, i.e., myxedema coma, hepatic encephalopathy due to valproate, central nervous system infections, neurodegenerative disorders, persistent vegetative states, serotonin syndrome, autoimmune encephalopathy, septic encephalopathy, or seizures. Negative tests and positive response to benzodiazepine makes catatonia most likely etiology in this case.

The underlying pathophysiologic mechanism for catatonia is likely heterogeneous. It has been proposed that basal ganglia thalamo-cortical circuit dysregulation with resulting changes in neurotransmitter function is a potential precipitant factor. ${ }^{[3]}$ Catatonic patients have lower gamma-aminobutyric acid A (GABA A) activity in the orbito-frontal cortex than do healthy and psychiatric control patients. ${ }^{[4]}$ Benzodiazepines, which are GABA A agonists, are first-line therapy for catatonia. ${ }^{[5]}$

The modified Bush-Francis Catatonia Rating Scale (BFCRS) is a 23-item rating scale that provides a standardized schema for clinical examination. ${ }^{[6]}$ We used an algorithmic approach to the diagnosis and management of catatonia in the ICU as proposed by Saddawi-Konefka. ${ }^{[7]}$ A trial of 1-2 mg of IV lorazepam can produce immediate, impressive reversal of catatonic features. This is known as the "lorazepam test" and is associated with reduced catatonia scores on the BFCRS by $60 \%$ within $10 \mathrm{~min}$ and response rates of $60-80 \%$ within hours or days. ${ }^{[8]}$

Despite the lack of prospective randomized evidence, benzodiazepines are the gold standard in the treatment of catatonia. ${ }^{[9]}$ IV lorazepam is commonly used, starting with doses of $2 \mathrm{mg}$ daily, and titrating occasionally to total doses of 20-30 mg daily. Other treatment options include amantadine, zolpidem, memantine, valproate, and phenobarbital. ${ }^{[9-11]}$ Electroconvulsive therapy, the most successful treatment for catatonia, is usually reserved for patients with benzodiazepine-resistant catatonia. ${ }^{[12]}$

\section{Conclusion}

Timely recognition and treatment of catatonia in the critically ill patients with altered mental status is essential, given the substantial morbidity and mortality associated with the condition.

\section{Financial support and sponsorship Nil.}

\section{Conflicts of interest}

There are no conflicts of interest.

\section{References}

1. American Psychiatric Association. DSM-IV: Diagnostic and Statistical Manual of Mental Disorders. $4^{\text {th }}$ ed. Washington, DC: APA; 1994.

2. Daniels J. Catatonia: Clinical aspects and neurobiological correlates. J Neuropsychiatry Clin Neurosci 2009;21:371-80.

3. Northoff G. What catatonia can tell us about "top-down modulation": A neuropsychiatric hypothesis. Behav Brain Sci 2002;25:555-77.

4. Pandharipande P, Shintani A, Peterson J, Pun BT, Wilkinson GR, Dittus RS, et al. Lorazepam is an independent risk factor for transitioning to delirium in Intensive Care Unit patients. Anesthesiology 2006;104:21-6.

5. Kanemoto K, Miyamoto T, Abe R. Ictal catatonia as a manifestation of de novo absence status epilepticus following benzodiazepine withdrawal. Seizure 1999;8:364-6.

6. Bush G, Fink M, Petrides G, Dowling F, Francis A. Catatonia. I. Rating scale and standardized examination. Acta Psychiatr Scand 1996;93:129-36.

7. Saddawi-Konefka D, Berg SM, Nejad SH, Bittner EA. Catatonia in the ICU: An important and underdiagnosed cause of altered mental status. a case series and review of the literature*. Crit Care Med 2014;42:e234-41.

8. Rosebush PI, Mazurek MF. Catatonia and its treatment. Schizophr Bull 2010;36:239-42.

9. Deuschle M, Lederbogen F. Benzodiazepine withdrawal-induced catatonia. Pharmacopsychiatry 2001;34:41-2.

10. Obregon DF, Velasco RM, Wuerz TP, Catalano MC, Catalano G, Kahn D. Memantine and catatonia: A case report and literature review. J Psychiatr Pract 2011;17:292-9.

11. Lauterbach EC. Valproate for catatonia: Need for caution in patients on SSRIs and antipsychotics. J Neuropsychiatry Clin Neurosei 2002;14:84-6.

12. Yeung PP, Milstein RM, Daniels DC, Bowers MB Jr. ECT for lorazepam-refractory catatonia. Convuls Ther 1996;12:31-5. 